\title{
Ethical intuitionism and the linguistic analogy
}

\author{
Philipp Schwind \\ Institute of Philosophy, Centre for Ethics of the University of Zurich, Zurich, Switzerland
}

\begin{abstract}
It is a central tenet of ethical intuitionism as defended by W. D. Ross and others that moral theory should reflect the convictions of mature moral agents. Hence, intuitionism is plausible to the extent that it corresponds to our well-considered moral judgments. After arguing for this claim, I discuss whether intuitionists offer an empirically adequate account of our moral obligations. I do this by applying recent empirical research by John Mikhail that is based on the idea of a universal moral grammar to a number of claims implicit in W. D. Ross's normative theory. I argue that the results at least partly vindicate intuitionism.
\end{abstract}

ARTICLE HISTORY Received 3 November 2016; Accepted 9 August 2017

\section{Introduction}

Ethical intuitionists likeW. D. Ross adopt the common sense view that there is an irreducible plurality of types of ethically relevant considerations. They furthermore hold that there is no explicit method that determines how to move from facts about which morally relevant considerations there are in a given situation to a conclusion about what it would be right to do. In order to systematize our moral reasoning, ethical intuitionists provide an account of the types of considerations that are ethically relevant. ${ }^{1}$ To do this, they introduce a list of prima facie duties that always count in favour of or against doing an action, even if their strength - that is, their ability to defeat other prima facie duties with an opposite normative valence - depends on circumstances. W. D. Ross counts duties of fidelity, reparation, gratitude, justice, beneficence, self-improvement, and non-maleficence among them (Ross 1930, 21). Intuitionists believe that philosophers do not need to devise ingenious procedures or invent new rules to identify these principles; rather, they should focus on the moral principles that guide the common sense beliefs accepted by mature moral agents (Ross 1930, 41). 
According to Ross, we arrive at knowledge of those principles through a process he calls 'intuitive induction': By reflecting on the fact that in several concrete situations, certain morally relevant features constantly count in favour of or against an act, we come to recognize the self-evident truth that those features are prima facie duties. ${ }^{2}$

A main challenge for this position is that intuitionists need to explain what justifies belief in self-evident moral propositions. In response, Ross offers a foundationalist epistemology: Our reflected beliefs concerning the contents of prima facie duties express a'moral order [...] [that] is just as much part of the fundamental nature of the universe [...] as is the spatial or numerical structure expressed in the axioms of geometry or arithmetic' (Ross 1930, 29-30; see also $12 \mathrm{f}$. and 24). The reason that appeal to common sense carries evidentiary weight is that our convictions serve as 'the data of ethics just as sense-perceptions are the data of a natural science' (Ross 1930, 41). For many, Ross's foundationalism is the least plausible part of his theory, especially since he seems to assume its truth rather than offer a systematic defence of it. Contemporary intuitionists inherit this unresolved challenge.

But even if a satisfactory theory for the justificatory force of moral intuitions can be worked out - a number of promising solutions have been suggested ${ }^{3}-$ this does not go the whole way in vindicating Rossian intuitionism. There is a related and equally important issue that has received almost no attention: We need an account of the content of those intuitions as well as the rule system that underlies them. If we take seriously the intuitionist claim that the commonly held convictions of mature moral agents are the 'data of ethics', the goal of such an inquiry must be a descriptively adequate theory of 'what we really think' (Ross $1930,102)$. There are two issues here. First, we need to know the content of the reflected beliefs regarding paradigmatic morally relevant situations from which prima facie duties can be derived. Second, we need to establish the moral rules that underlie those beliefs.

30 To defend Rossian intuitionism, the descriptive and the justificatory projects are equally important and depend upon each other. For without justificatory force, intuitive moral judgments cannot ground a system of moral rules, and without knowing what mature agents believe, a moral theory that is based upon our moral intuitions remains empty.

35 In this paper, I will discuss recent evidence for such an empirically adequate account of moral intuitions and consider whether the results are compatible with Rossian intuitionism. This requires a number of steps. First, I address two arguments that challenge the relevance of descriptive adequacy for Ross's theory (Section 2). Then I discuss which empirical assumptions are implicit in

40 moral intuitionism (Section 3). In order to test these, I briefly introduce Noam Chomsky's linguistic program and John Rawls's case for applying the same methodological framework to morality (Section 4). Following that, I explain the setup of John Mikhail's empirical work in moral psychology and discuss how it relates 
to Chomskyan linguistics (Section 5), and I present the moral rules and the account of moral deliberation that Mikhail believes can be derived from the data (Section 6). At first glance, a comparison between these results and Ross's theory suggests that his intuitionism fails to be empirically adequate (Section 7), but a closer look at the differences between Mikhail's results and Rossian intuitionism reveals that either the differences do not undermine Ross's claim of descriptive adequacy or they can be traced to theoretical disagreements between Ross and Mikhail (Sections 8-10).

\section{Ross and descriptive adequacy}

10 Before turning to the main question regarding descriptive adequacy, the claim that descriptive adequacy is even relevant for Rossian intuitionists must first be defended against two challenges. The first and more fundamental worry is that normative principles cannot be derived from a descriptive account of moral judgment. Ross himself was an adamant defender of the view that right' is an

15 irreducible notion and cannot be explained in non-moral terms (Ross 1930, 12). Consequently, he was doubtful about the school of sociologists who 'seek to replace moral philosophy by the 'science of mours', the historical and comparative study of the moral beliefs and practices of mankind' (Ross 1930, 13). He argues that this form of inquiry reduces moral beliefs to societal and historical circumstances, suggests a sceptical attitude towards them, and ignores that moral beliefs have truth-values. Even if granted, however, these points do not undermine the importance of descriptive adequacy for Rossian intuitionism. The purpose of analysing the well-considered judgments of mature agents is not to leap from descriptive to normative facts, but to make use of an epistemically privileged perspective that reveals basic moral principles. If it can be shown that those well-considered judgments enjoy an elevated epistemic status - a core Rossian claim that requires a separate defence - then the fact that the content of those judgments can be determined by finding out what those agents believe under descriptively characterized circumstances is in itself not problematic. It is also in line with other core intuitionist beliefs. Ross, for example, seeks to establish the superiority of his view by showing that it aligns more closely than competing theories with common sense, with what 'seems clear', 'is plain on reflection', conforms 'to what most men (if not all) believe', etc. (see, among other references, Ross 1930, 2, 6, 8f., 11, 17, 18, and especially 39f.). In one of his most frequently quoted passages, Ross claims that 'it is more important that our theory fit the facts than that it be simple', and for him, the way to discover those facts is to consult 'what we really think' (Ross 1930, 30). Therefore, determining what common-sense morality consists of is part of the intuitionists' project.

Second, it might be asked whether idealized judgments would not be a better source of insight than those of actual agents, with their cognitive errors and psychological biases (for the claim that moral intuitions are systematically 
distorted, see Sinnott-Armstrong 2006, 184-219). This line of attack does not question the inference from judgments made under certain circumstances to normative conclusions; instead, it asks what kind of adequacy is required for the judgments that intuitionists rely on. It is important to note that there are more than two options here: The extremes are well-considered judgments of hypothetical agents under idealized circumstances at one end and the unfiltered opinions of everyday people collected in a random poll at the other. Intuitionists place themselves between those poles. Ross occupies a middle position by relying on the common sense opinions shared by his contemporaries, but adding mental maturity and careful deliberation as preconditions (Ross 1930, 29). He also requires that what appears to be self-evident to us must not contradict other firmly held convictions (Ross 1930,41$).{ }^{4}$ This explains why intuitionists see no contradiction in relying on actual commonly held moral views while at the same time excluding the distortions that impact many of our everyday moral judgments. However, a challenge for descriptive adequacy is that it needs to be shown how an empirically informed account can incorporate these epistemic filters.

Once the need for descriptive adequacy has been recognized, it follows that many of the claims that intuitionists have so far believed to reflect common sense morality should be treated as hypotheses that need to withstand empirical scrutiny and that are potentially subject to revision. ${ }^{5}$

\section{What empirical claims does Rossian intuitionism make?}

There are three possible outcomes for an empirical study into the principles that underlie the common sense judgments of mature agents. First, there is a chance that no universally shared set of rules can be found; instead, different individuals or groups adhere to diverse fundamental moral principles. This would weaken the intuitionist assumption that there is one rule system that is shared among all agents. A second, less pessimistic outcome would still be a burden for intuitionism: This is that there is a list of prima facie duties that is stable across individuals and cultures but that differs significantly in content from the classical intuitionist picture. This would require revisions in the intuitionists' normative account and might undermine some of Ross's arguments against his utilitarian competitors. A third possibility is that a review of evidence collected by empirical moral psychology might confirm many of Ross's armchair intuitions and therefore strengthen his theory.

In order to ascertain which of these outcomes is correct, we first need to formulate the empirical predictions that are implicit in Rossian intuitionism. After a method for analysing common sense morality has been identified and applied, the results can be interpreted and matched against the empirical

40 predictions. Here is a list of central assumptions to which Rossian intuitionists subscribe: 
(1) Despite disagreements about concrete issues, mature moral agents (implicitly) rely on the same fundamental morally relevant features and apply them in their deliberations. ${ }^{6}$

(2) There is a plurality of basic morally relevant features (see the list of prima facie duties in Ross $(1930,21 \mathrm{f}$.)).

(3) Those features can be expressed in the form of prima facie principles: The moral rules determine whether the relevant features count in favour of or against an act, but their relative strength depends on context (Ross 1930, 19f.).

(4) Mature agents can gain knowledge of prima facie duties via intuitive induction (Ross 1930, 32-34).

(5) The principles that underlie the judgments of morally mature agents bear a resemblance to Ross's list of prima facie duties (see above); minimally, the rules contain both consequentialist and deontological principles (Ross 1930, 21f).

It would be remarkable if all of these predictions were vindicated from an empirically informed point of view. More realistically, even a partial match between these assumptions and an empirically adequate picture would testify to Ross's highly refined sense of moral imagination. For the purpose of comparing Ross's

20 assumptions with recent research in empirical moral psychology, I will first introduce some distinctions from modern linguistics and then show how they can be applied to morality. This is necessary since the empirical study of commonly held moral views with the most developed technical apparatus and the broadest empirical support draws its resources from Chomskyan linguistics.

\section{4. Chomskyan linguistics and its application to morality}

Chomskyan linguistics makes the case for a generative grammar, which is a set of rules possessed by all competent speakers that allows them to judge whether a sentence in a given language is grammatical. ${ }^{7}$ Two distinctions are relevant for understanding the kinds of rules that form the generative grammar. The first differentiates between competence and performance. Competence refers to the linguistic knowledge necessary to understand and judge sentences in a given language; in contrast, performance describes a speaker's actual linguistic behaviour, which is also influenced by 'grammatically irrelevant conditions such as memory limitations, distractions, shifts of attention and interest, and errors' (Chomsky 1965, 3). The goal of Chomskyan linguistics is to isolate a speaker's competence. The second distinction concerns two kinds of principles that explain our judgments about language (Mikhail 2011, 19-21). Operative principles are those principles that explain our language use. The explanations speaker offer for their language use are called 'express principles'. Since competent language users can - and, Chomsky argues, in fact do - make mistaken 
assumptions about the principles that govern the exercise of their ability to speak a language, there can be discrepancies between operative and express principles. Given the goal of determining the rules that are necessary for mastering a language, Chomsky is interested in operative principles. Hence, two important conditions underlie Chomsky's formulation of generative grammar: He abstracts from performance in order to analyse linguistic competence, and he denies that people have access to the grammatical rules they rely on.

Although originally developed as a linguistic theory, Chomsky's account has been applied to areas ranging from mathematics, music, and object perception to our ability to classify animals and plants (Hauser, Young, and Cushman 2008, 109; Sripada 2008, 319). This broad range of application raises the question of whether Chomsky's account can also provide an explanation of moral judgments. In fact, the idea that the principles that guide our moral intuitions are structurally similar to the rules of grammar predates modern linguistics.

15 Adam Smith, for example, wrote in a famous passage from The Theory of Moral Sentiments that

[t]he rules of justice may be compared to the rules of grammar; the rules of the other virtues, to the rules which critics lay down for the attainment of what is sublime and elegant in composition. (Smith [1759] 2002, 205)

20 Starting with Rawls, philosophers have suggested that Chomsky has formulated an empirical theory that can be used to test the analogy between linguistics and morality. Rawls (1971, 40-42) argues that our 'sense of justice' can be analysed using the same methodological distinctions that Chomsky draws. In recent years, moral psychologists such as John Mikhail have advanced the idea of a 'linguistic analogy' by conducting large empirical studies of people's judgments regarding a number of moral dilemmas modelled after 'trolley cases' (Mikhail 2011). ${ }^{8}$ In line with Rawls's predictions, those studies provide an empirical argument in favour of structural similarities between linguistics and morality. They also identify what the main traits of our moral grammar might plausibly look like.

30 Even though Mikhail's aim is to provide an interpretation of Rawls's early work (Mikhail 2011, 10f.), which stands in competition with intuitionism, the results of his study can also be used to test the empirical assumptions of Ross's theory. ${ }^{9}$

\section{An empirically adequate account of moral judgment}

In analogy with modern linguistics, two distinctions need to be made (Mikhail 2011, 50-55). As in Chomsky's theory, there is a difference between moral performance and moral competence. Moral judgments are often affected by factors such as fear, mistaken beliefs, time pressure, etc. In order to eliminate these distorting influences, moral psychologists aim to elicit responses under ideal circumstances. It is from these judgments that the moral grammar has to be 40 derived. The second distinction differentiates between operative and express principles. Instead of relying on the often erroneous explanations that test 
subjects offer for their own judgments (express principles), moral principles are determined by analysing response patterns to test cases (operative principles). ${ }^{10}$ An empirical account of moral judgment that is modelled after Chomskyan linguistics needs to incorporate those two distinctions. This is how Mikhail does it: He presents test subjects in a controlled setting with a range of hypothetical scenarios that are modelled after Philippa Foot's 'trolley cases', especially the scenario of the bystander and the footbridge (Foot 1967). The judgments people offer in response to these problems are then analysed in search for an underlying rule system. Since the interpretation of these data is not based on the explanations that test subjects give for their responses, the analysis of trolley cases identifies plausible candidates for operative principles. More challenging is the question of whether responses to trolley cases reveal moral competence or moral performance. Since test subjects are 'disinterested third parties [...] in relaxed settings where they have plenty of time to rely on all of their moral

15 capacities' (Mikhail 2011, 96), it can be assumed that the experiment tests for competence; In addition, their responses are 'stable, stringent, and highly predictable' (83). This provides at least indirect evidence that the data are free from distortions - for otherwise, psychological defeaters would be present in some test subjects yet not in others, resulting in 'noisier' patterns of responses. Also,

20 in line with assumptions introduced above, the test subjects are, regardless of their age, gender, and level of education, unable to offer explanations that are consistent with their judgments (Mikhail 2011, 110).

Reactions to trolley cases and their variations should provide insight into the process of moral decision-making in virtue of the fact that with a fairly 25 simple scenario, they instantiate a number of central moral concepts such as the significance of consequences, respect for rights, the means/end-distinction, and the difference between intended and foreseen consequences. Furthermore, the test subjects are required to judge the deontic status of possible courses of action, where the options are limited to unambiguous responses (allowed/

30 forbidden) that allow comparison of similar cases. This turns the abstract problem of formulating a descriptively adequate account of moral knowledge into the concrete task of finding rules which explain a set of specific judgments (see Mikhail 2011, 102f).

Another feature of Mikhail's test cases is the fact that they avoid conflicts 35 between competing deontic rules. Instead, there is only one moral principle that needs to be taken into account in each scenario. ${ }^{11}$ This way, Mikhail avoids disagreements that are due to differences in how agents weigh competing morally relevant features against each other. ${ }^{12}$ Hence, the results of his experiments are limited to what morally relevant features there are, but are silent on how those

40 features interact (for further discussion on the significance of this limitation, see Section 10).

An important qualification regarding the nature of the argument needs to be made. Even if the empirical evidence was as strong as possible, this would not 
count as a conclusive demonstration of a linguistic analogy between language and morality. Given the defeasible nature of arguments based on empirical data, such an argument would only offer presumptive and defeasible evidence. However, it has to be admitted that the data Mikhail uses as empirical evidence is far from perfect: to mention two problems, the sample Mikhail's study relies on is not as representative as it could be. ${ }^{13}$ There is a further problem. For many test cases, a vast majority of participants share the same intuitions. In some of the scenarios however, a considerable percentage of test subjects diverges from the majority view. ${ }^{14}$ Both facts weaken any conclusion that can be drawn from Mikhail's data. Despite these shortcomings, there is significant agreement in most of his test-cases that can plausibly be interpreted as speaking in favour of an analogy between morality and Chomskyan linguistics. It is however important to keep in mind that an argument that relies on Mikhail's empirical work is fallible and certainly less than demonstrative.

In the Section 6, I will briefly introduce the results of Mikhail's study before highlighting some concerns.

\section{Deontic rules}

The first principle can be expressed as a version of the principle of double effect $^{15}$ :

An otherwise prohibited action, such as battery or homicide, which has both good and bad effects may be permissible if the prohibited act itself is not directly intended, the good but not the bad effects are directly intended, the good effects outweigh the bad effects, and no morally preferable alternative is available. (Mikhail 2011, 149)

The second rule is the 'Principle of Natural Liberty' or 'Residual Permission Principle', according to which an act is forbidden if it 'has features F1 ... Fn [...]; otherwise, it is permissible' (Mikhail 2011, 133). In other words, if a particular action does not fall under any rule specified by the moral grammar, the action counts as morally permissible.

As a third deontic rule, Mikhail introduces the prohibition of battery and homicide (Mikhail 2011, 133-137). Battery is defined as'causing harmful contact with a person without her consent' (134); both homicide and battery are done in a way that is either purposeful or knowingly (133f.).

The fourth rule is the self-preservation principle. Its purpose is to define the circumstances under which it can be assumed that a person would not consent to an action. In Mikhail's formulation it states that 'if a harmful contact with a person necessitates killing her, then she would not consent to it' (Mikhail 2011, 137). ${ }^{16}$

Fifth, the moral calculus of risk specifies good and bad effects and ranks them. Mikhail postulates three primary bad effects in the ordinal ranking: death, bodily harm, and the destruction of a valuable thing (Mikhail 2011, 137-144). 
Furthermore, according to this principle, values can be aggregated, e.g. the death of more people is worse than the death of fewer people. When comparing bad effects of different kinds (e.g. whether a death is worse than a bodily harm), the chances that the bad effects will occur also needs to be taken into account.

Finally, Mikhail adds a rescue principle to the list. It prohibits failing to rescue an endangered person, although not at all costs: This duty is lexically ordered and subordinate to other principles, such as the prohibition of homicide or battery.

What form does the process of moral reasoning that leads to deontic judgments take? In answer to this question, Mikhail argues that the deontic rules provide 'necessary and sufficient conditions for assigning a deontic status to a given act or omission. The reasoning can therefore be captured with the following schema:

A has deontic status $D=A$ has features $F 1$... Fn.

$A$ has features $F 1$... Fn.

A has deontic status D. ${ }^{17}$

Since the schema allows for mechanical application going from the features present in a given situation to the respective deontic rule, the agent does not need to be a human being but could, Mikhail argues, also be a machine. Comparing moral deliberation to the calculation of a chemical reaction, he proposes that trolley cases (and presumably all moral problems) can be matched against a'periodic table' (Mikhail 2011,153-162) that indicates which elements (such as homicide as an end or means or a side effect) a scenario instantiates.

\section{Comparing the linguistic analogy with Rossian intuitionism}

At first glance, a comparison between the results of Mikhail's linguistic analogy and Ross's theory suggests that there a few things they can agree on. However, while both hold that all moral agents share a common set of moral rules and that there is a plurality of morally relevant features (Ross's first and second empirical claims), the commonalities end there. While Ross believes that these features can be expressed as prima facie duties (his third empirical claim), Mikhail's schema leaves no room for conflict between principles (see Section 6). Contrary to the fourth empirical claim implicit in Rossian intuitionism - the idea that agents can gain epistemic access to fundamental moral rules - Mikhail denies that express principles allow insight into the rules that govern moral judgments. Finally, Mikhail's list of deontic rules bears little resemblance to Ross's catalogue of prima facie duties.

Does it follow, then, that ethical intuitionism fails in terms of descriptive adequacy? Before jumping to a hasty conclusion, we should consider whether Rossian intuitionists might be able to reject some of Mikhail's claims and accommodate those they can't reject. I will begin by discussing whether the data 
commit Mikhail to denying that agents can know the content of the deontic rules, then I will turn to the differences between the lists of duties, and finally I will consider the question of whether the empirical evidence contradicts Ross's claim that fundamental obligations take the form of prima facie duties.

\section{The relation between moral and linguistic grammar}

In Chomskyan linguistics, the distinction between operative and express principles means that the rules of grammar'are assumed to lie beyond [the] actual and even potential consciousness' of competent speakers (Mikhail 2013, 19). Does the same hold for morality? At places, Mikhail argues that analogously to the linguistic case, moral agents have no direct cognitive access to the content of their moral grammar (Mikhail 2011, 20). In later publications, however, he takes a more careful stand (Mikhail 2013,5). There are indeed good reasons to be more cautious. In the case of linguistics, the fact that we have no access to the principles that guide our behaviour does not affect our linguistic practices:

15 Competent speakers do not normally face the need to appeal directly to the principles of grammar in order to justify their linguistic judgments. Things are different for the moral case. Even though in most situations, mature agents as their responses to trolley cases indicate - have no difficulty in dealing with moral problems, there are issues at the individual and societal level where even under idealized circumstances, people are unclear about their own judgments or disagree with one another. In these instances, progress can often be made by considering which moral principles underlie our judgments in less controversial cases and then applying them to the problem at hand. For example, in discussions about abortion or assisted suicide, appeals to principles such as autonomy and human dignity are a familiar strategy for justifying one's position. While it is reasonable to assume that people often err when reconstructing the rules that guide their moral judgments - this is confirmed by Mikhail's study (Mikhail 2011, 78) - there are also reasons to believe that with careful deliberation, it is possible for people to access basic moral principles. If the rules of our moral grammar were always inaccessible to mature agents, it would not be possible to explain why Ross's prima facie duties - which are supposed to be derived from 'what we really think' - bear a resemblance to Mikhail's list of deontic principles (more on the comparison between the two below). Further, even where Mikhail's moral grammar goes beyond Ross's theory, his principles resonate with common sense and have long been discussed in moral philosophy. The doctrine of double effect, for example, was first discovered when Aquinas reflected on the permissibility of self-defence (Aquinas 2012, II-II, Qu. 64 , Art. 7). The prohibition of battery and homicide, to take another example, is an undisputed part of common sense morality.

40 Still, this does not amount to the claim that there is no difference between operative and express principles when it comes to morality. The argument 
merely suggests that there is no strict dichotomy: In most instances, stipulations about the principles that guide our moral judgments are unreliable; however, under certain circumstances including careful deliberation, mental maturity, and the absence of psychological defeaters, agents are nevertheless able to identify these principles. ${ }^{18}$ So the distinction is strong enough to support Mikhail's point that as a methodological maxim, explanations of moral judgments should not rely on express principles, but at the same time there is enough room for Rossian intuitionists to insist that under the right conditions, we are able to identify prima facie principles.

\section{The divergence between Mikhail's deontic principles and Ross's list of prima facie duties}

As the Table 1 illustrates, Mikhail's list of deontic rules only partly overlaps with Ross's; in addition, each of their accounts includes rules that are not matched by the other's account.

There are two points that taken together help to explain the divergence of the accounts without challenging the validity of either theory. First, neither Ross nor Mikhail claims that their account is final. Indeed, Ross explicitly asserts the preliminary character of his catalogue of duties (Ross 1930, 23). ${ }^{19}$ It would

Table 1

\begin{tabular}{ll}
\hline Ross & Mikhail' \\
\hline Fidelity & - \\
Reparation & The prohibition of intentional battery and homicide \\
Gratitude & The life of one person has as much moral worth as the life of any other ${ }^{2}$ \\
Non-maleficence & The rescue principle \\
Justice & - \\
Beneficence & The principle of self-preservation \\
Self-improvement & The moral calculus of risk \\
- & The doctrine of double effect \\
\hline
\end{tabular}

'As Mikhail $(2011,25 f$.) stresses, there are further 'elements of moral cognition' that must be presupposed as part of the moral grammar, such as the basic principles of deontic logic and of first-order logic, causal concepts, etc. Since the present focus is on deontic rules, I omit those additional assumptions. Even though there is no discussion of the issue in Ross, it is plausible that he also needs to presuppose these further elements. The same goes for the closure rule: since it is a second-order rule specifying the completeness of Mikhail's list of deontic rules, I have not included it in the table. Ross shares the same belief: For him, the list of prima facie duties specifies all morally relevant rules.

${ }^{2}$ See Mikhail $(2011,167)$. Although this principle, which Mikhail does not deem a deontic rule, does not directly correspond to Ross's prima facie duty of justice, which is concerned with the distribution of pleasure in accordance with merit, both rules can be taken to be motivated by the same concern: Human beings are equal and merit the same treatment unless an unequal treatment is justified by a relevant difference.

${ }^{3}$ Strictly speaking, the moral calculus of risk and the doctrine of double effect do not belong in a list of prima facie duties, as on their own they do not offer reasons in favour of or against an act. Rather, they either specify what counts as a good and bad effect or indicate under what circumstances otherwise prohibited actions are permissible. I nevertheless include them here because they are necessary for explaining common sense morality, and insofar as Ross wants to offer a complete account of our moral judgments, he cannot ignore them. 
require serious argument to convince either side to give up elements on their list, but the addition of new items should require less effort since this doesn't call into question those duties that have already been established. Second, where Mikhail and Ross differ, they don't disagree about the same phenomenon but rather focus on different areas of moral discourse. Mikhail's aim is to explain a narrow set of scenarios that involve harming or saving other people; fidelity, reparation, and gratitude play no role in the trolley scenarios on which his account is based. In contrast, Ross focuses on cases that consequentialism has difficulty accounting for, such as promising or duties of gratitude. ${ }^{20}$ Ethical problems whose solution presupposes, for example, the doctrine of double effect or the principle of self-preservation are therefore not on his radar. Hence, it is possible that if Mikhail and Ross had considered a wider scope of cases, they might have come to the same conclusion regarding the list of fundamental moral principles. As it stands, the present disagreement between Mikhail and Ross therefore cannot be taken to count against the descriptive adequacy of ethical intuitionism.

\section{Are there prima facie duties?}

A fundamental difference between Ross and Mikhail concerns the way in which rules interact in cases of conflict. As seen above, Mikhail's picture of moral deliberation leaves no room for the weighing of competing moral principles: His rules serve to specify which features correspond to which deontic status. Once the presence of those features has been established, the deontic status is determined (Mikhail 2011, 91-93 and 124f.). No further deliberation regarding the weight of various morally relevant aspects of the situation is needed. Any 'machine capable of computing judgments' can apply the rules: Mikhail compares the task of the moral psychologist to that of an 'engineer faced with the task of designing [such] a machine' (Mikhail 2011, 27). Trolley cases fit this model. Even though in most of Mikhail's variations, the action has good and bad consequences, there is a single principle that determines the right action. In contrast, it is a central part of Ross's theory that conflicts of duties are possible and

30 there is no general rule that specifies how the principles interact; even though the same morally relevant features always count in the same direction (i.e. in favour of or against performing the action), their weight depends irreducibly on context. This is why Ross calls his moral principles 'prima facie duties'. For Mikhail's theory to serve as a model for Rossian intuitionism, it would have to be able to handle cases where moral principles conflict, and a theory modelled on a device that computes deontic verdicts from fixed rules is unable to achieve that. ${ }^{21}$ Alternatively, Rossian intuitionists would have to give up a central tenet of their view.

Zimmerman challenges Mikhail on this point. In one of his examples, the

40 doctrine of double effect applies but is trumped by a competing moral consideration (Zimmerman 2013, 12f). There, the killing of a person is necessary 
in order to save a very large number of other people. Many would judge this act as permissible, even though it is forbidden according to the doctrine of double effect since the bad effect is not merely foreseen, but also intended. In order to accommodate these kinds of cases, Mikhail's deontic rules should, as Zimmermann argues, be given a 'comparative form' (Zimmerman 2013, 13), which would allow them to be weighed against other relevant normative considerations before arriving at an all-things-considered judgment.

In response, Mikhail argues that counterexamples such as Zimmerman's should be treated as special cases that have to be codified as part of the moral principle (Mikhail 2013, 16-19). ${ }^{22}$ This way, their occurrence will become an instantiation of the rule and cease to be a counterexample. ${ }^{23}$

This approach reduces the serious challenge that Mikhail's moral grammar hypothesis is built on the wrong kind of rules to the already familiar and solvable issue that, in order to do justice to a larger set of cases, he needs more fine-

15 grained principles. This move, however, comes at a cost. In order to solve the problem, the procedure has to be repeated for every possible case that could be construed as a conflict between a deontic rule and other relevant considerations. Moreover, a simple lexical ordering of rules would not do the trick: Depending on the circumstances, deontic rules have to be assigned different degrees of strength, giving rise to an enormous, perhaps infinite number of configurations to be incorporated in the rule system. If it is the case that most choices we are confronted with in everyday life involve more than one moral obligation, and if the exact weight of those obligations differs from case to case, then the complex moral grammar accounting for all of those complications would resemble 25 a linguistic grammar that had a different rule for almost every sentence. Thus, the complexity of the moral grammar would increase dramatically compared to Mikhail's original proposal, making it doubtful that such a system could be stored by the finite capacity of the human brain. The point is not that the most accurate formulation of the moral grammar cannot include specifications that

30 limit or describe the application of deontic rules in specific circumstances. ${ }^{24}$ Rather, the lesson is that this strategy cannot solve the problem in its totality.

The challenge of explaining conflicts of duties brings out a trilemma in Mikhail's theory. These are the three commitments that follow from his view:

(1) the 'traditional deductive model of moral judgment' (Mikhail 2013, 19) expressed in his schema of moral reasoning,

(2) a moral grammar whose content is simple enough to be stored by the finite cognitive capacities of the human brain, and

(3) a system of deontic rules that is complete insofar as it explains all moral judgments.

40 The first claim is a commitment that Mikhail makes explicitly (see above). The second claim is an assumption that he is implicitly committed to: Insofar as the moral grammar is the result of analysing the actual judgments of mature agents, 
it must be within the grasp of our mental capacities. The analogy between linguistics and morality motivates the third claim: Just as linguistics aims to uncover the basic rules of the generative grammar that underlies our linguistic competence, it is the goal of the linguistic analogy to explain our ability to make moral judgments, and this does not allow for areas of moral discourse that remain unaccounted for by the theory.

If, as argued above, the traditional deductive model of moral judgment entails that no further mental operation beyond the application of the deontic rule to a situation is necessary for reaching a moral verdict (first commitment), and if the moral grammar covers all possible complications (third commitment), then the second commitment cannot be maintained since the resulting system of rules would exceed our mental limitations. This, however, would defeat the very purpose of the moral grammar hypothesis. Instead, either the first or the third claim has to be rejected. Rejecting the third claim would save the theory,

15 but also at a very high cost: If only a fairly limited range of cases would be covered by the hypothesis, this limited explanatory power wouldn't suffice for a general account of moral intuitions. However, then there would be no unified explanation of the rule system that underlies widely held moral judgments, a core goal of Mikhail's theory. The least costly option, it seems, is to dismiss the first claim. Even though Mikhail is committed to it, seeing himself as executing a research program envisioned by a long tradition of thinkers (Mikhail 2013, 28), ${ }^{25}$ the claim is contrary to deep-seated beliefs about the nature of morality that are hard to reconcile with the idea that our moral intuitions could be generated (possibly in a superior way) by machines executing a moral code. As a matter of fact, the idea that we often need to weigh morally relevant facts against one another without having a rule that determines in advance how to do so seems so firmly embedded in common sense that it is hard to accept that we even need empirical evidence for this claim. ${ }^{26}$ I will therefore pursue the option of rejecting the first claim and consider what follows from this for the nature of 30 moral deliberation.

The reason for the overbearing complexity of the moral grammar in the case where the first and third claim are taken to be correct is that the system of rules needs to simultaneously provide two kinds of information: Given a description of a situation, an agent in possession of the moral grammar knows (a) what morally relevant features count in favour of or against the action and (b) what their relative strength is. Compared to the information that a rule speaks in favour of or against an action, codification of how the rule interacts with other morally relevant factors is far more complex. To reduce this complexity, a natural move would be to give up the goal of finding a rule system that can determine

40 the weight of each morally relevant consideration in advance. Instead, this task could be performed by a judgment about the relative weight of the morally relevant factors that bear on a situation that cannot be captured by a codified system. ${ }^{27}$ 
As a result, we should revise Mikhail's understanding of moral deliberation as a'logically closed system' (Mikhail 2011,124) and make room for the application of moral judgment. The revision takes the following form:

Prima facie reason $\mathrm{P}$ applies to $\mathrm{A}=\mathrm{A}$ has features $\mathrm{F} 1$... Fn.

Prima face reason $\mathrm{Q}$ applies to $\mathrm{A}=\mathrm{A}$ has features $\mathrm{F} 1 \mathrm{x}$... Fnx.

$\cdots$

Agent $X$ assigns a relative weight to prima facie reasons $P, Q, \ldots$

Agent $X$ determines the all-things-considered judgment.

A has deontic status $D$.

10 In case only one prima facie reason bears on a situation, there is no need for the exercise of moral judgment, as the all-things-considered judgment about the moral permissibility of the action follows directly. Mikhail's trolley cases fall into this cate-gory.

This model offers distinct advantages over Mikhail's picture. If Ross is right, at least in principle, and the number of irreducible prima facie duties is small, the complete moral grammar does not face the challenge of being too complicated to be accommodated by a limited cognitive system. In addition, once all fundamental moral considerations have been added to the moral grammar, this relatively sparse technical apparatus can explain a much wider range of cases than Mikhail's original theory (which was only designed to account for a small number of trolley cases). And pace Mikhail, this theory does not support the implausible claim that complex and context-sensitive moral judgments can be reduced to an algorithm executable by a machine.

In contrast to Mikhail's other claims, his rejection of fundamental moral principles as prima facie duties is not necessitated by the empirical evidence. Even though this rejection is compatible with Mikhail's empirical work - the cases he considers are designed in such a way that a single moral principle explains them, and therefore they don't commit him to a stance regarding more complex situations where several duties apply - the view that there is only one principle that bears on each situation is a deliberate choice that expresses his theoretical preferences. As such, the disagreement between the two views has to be resolved through non-empirical means such as an appeal to common sense. Here Ross's view has, as I have just shown, more plausibility. This places the burden on Mikhail to demonstrate that the advantages of his view outweigh the apparent advantage of Ross's theory. Hence, the fact that Ross's view corresponds to deep-seated intuitions about the nature of fundamental moral principles gives us strong reason to adopt his position regarding prima facie duties.

\section{Conclusion}

Is Rossian intuitionism an empirically adequate theory? In light of the preceding discussion, intuitionists are entitled to a qualified positive answer. Some of 
Ross's empirical assumptions have straightforwardly been vindicated: Mikhail's study has provided new evidence that mature moral agents rely on the same fundamental morally relevant features (Ross's first assumption). Further, there is a plurality of basic morally relevant features (Ross's second assumption). It is a matter of debate whether these features can be expressed in the form of prima facie duties (Ross's third assumption), but as I have shown above, it is reasonable to expect that further studies might reveal that, pace Mikhail, moral principles have to be weighed against each other. It is also a matter of dispute whether agents can gain knowledge of prima facie duties (Ross's fourth assumption). Finally, the divergence between Ross's and Mikhail's lists of duties can mostly be explained by their different theoretical goals. In case some divergences remain even after the difference in goals has been taken into account, Rossian intuitionists would most likely have to revise those parts of their theory.

Two further lessons emerge from this discussion. First, as a general theme, an empirically adequate picture of morality cannot easily be read from the data, but relies on implicit assumptions that are philosophical rather than empirical in nature: What kinds of scenarios would be philosophically interesting and should therefore be examined through empirical testing? What should we expect people to know? What is the nature of moral deliberation? The second lesson follows from the first: Not only do the empirical predictions of Rossian intuitionism need to be measured against Mikhail's empirical study, but Mikhail's analysis can also be improved by paying attention to Ross's theory, as the previous discussion about the nature of moral reasoning about duties has shown.

As is the nature of any theory that relies on common sense, ethical intuitionism is situated at the intersection between two forms of inquiry. In order to be convincing, Rossian intuitionists not only have to defend the conceptual claim that moral principles are self-evident and that this fact gives warrant to those principles; they also need to demonstrate that the content of their normative theory explains the actual well-considered moral judgments of mature agents.

30 Recent findings in empirical moral psychology have significantly improved our understanding of this question, and future research will certainly continue to do so. It might seem unsatisfactory that, as a result, the intuitionist project of formulating an ethics based on common sense morality remains open to challenge from empirical disciplines. However, this should not be taken as a weakness of the theory. Quite the opposite, being true to theory and practice is a virtue that sets intuitionism apart from its competitors.

\section{Notes}

1. In this paper, I will limit my discussion to the kind of intuitionism that is developed by W. D. Ross. Therefore, unless specified otherwise I will use the term 'intuitionism' to denote Ross's version of the theory. I will also only be concerned with Ross's deontic theory and will ignore his axiological views. 
2. Ross does not use 'induction' in the enumerative sense according to which our confidence increases with sample size. Rather, he describes it in his commentary on Aristotle as 'the process whereby after experience of a certain number of particular instances the mind grasps a universal truth which then and afterwards is seen to be self-evident' (Ross 1977, 223). For an application of this Aristotelian theory to his own moral epistemology, see Ross (1930, 32f.) and Ross (1939, 170).

3. Audi argues that by understanding a self-evident proposition, we apprehend its relation to abstract entities (Audi 2013, 167). Cuneo and Shafer-Landau (2014) make the case that certain moral statements ('moral fixed points') are a species of conceptual truth. Stratton-Lake (2014) proposes that what justifies self-evident propositions is not the fact that we understand them in a certain way; while this is necessary for getting a clear grasp of the proposition at stake, the fact that it seems true to us does the justificatory work.

4. There is a valid worry that in order for the appeal to well-considered judgments of mature agents to have evidentiary weight, there must be a neutral characterization of moral maturity. Otherwise, the intuitionist could simply pick those kinds of agents whose judgments mirror her own pre-theoretical convictions. Fear and disgust, for example, are by some taken to be a reliable moral guide (which might lead to intuitions about duties towards one's family, culture or nation), while Rossian intuitionists might consider this a distorting influence and rather focus on the intuitions of calm and reflective agents. If there is no non-question-begging way to choose one kind of moral maturity over another, the worry goes, the intuitions of one's preferred kind of mature agents cannot speak in favour or against a normative theory. A defender of Ross's theory has two replies. First, he can point out that many of the prima facie duties on Ross's list would result from most plausible conceptions of moral maturity. It is in fact hard to imagine what kind of mature agent would deny that we have prima facie duties to keep promises, not to injure others or to benefit others if possible (I am leaving aside more contentious items on Ross's list, such as his duty to self-improvement; acceptance of those rules is not necessary for being a Rossian intuitionist. Contemporary defenders of Rossian intuitionism such as Robert Audi omit them as well (see Audi 2004, 161-196). The question then becomes whether there are considerations beyond those on Ross's list that should also be included. Here, intuitionists could argue that obligations such as those towards one's family or nation are not proper candidates for the list of prima facie duties because they are not basic and can be derived from the items already on the list. Ross himself makes use of such an argument when he tries to show that duties towards one's country follow from the prima facie duties of gratitude and fidelity (see Ross 1930, 27f.). Hence, Ross offers a thin normative theory consisting merely of basic moral considerations which is compatible with various substantive normative views (see Ross 1930, 30). I thank an anonymous referee for raising this issue.

5. In line with this claim, Ross $(1930,23)$ explicitly allows for the possibility that there are prima facie duties that he has overlooked. Railton $(1986,206)$ also argues that the ethical intuitionist needs to provide an epistemological account that is 'psychologically plausible'.

6. Ross $(1930,23)$ : 'It is a prima facie classification of the duties which reflection on our moral convictions seems actually to reveal. And if these convictions are, as I would claim that they are, of the nature of knowledge, and if I have not misstated them, the list will be a list of authentic conditional duties ...', and ' $[t]$ he account we have given above corresponds (it seems to me) better than either of the simpler theories with what we really think ...'(19). 
7. Chomskyan linguistics also addresses the question of how knowledge of a language is acquired (the theory of universal grammar) and the issue of how the knowledge of language is put to use (the theory of linguistic performance). For present purposes, I set those problems aside.

8. Other notable related work includes Harman and Roedder (n.d.), Hauser (2006), Hauser, Young, and Cushman (2008), and Dwyer (2007).

9. The only other philosopher that I am aware of who has considered the application of Chomskyan linguistics to intuitionism is Hare. However, Hare quickly dismisses the idea: In Hare's narrow construction of the analogy, Chomsky's focus on the structural features of language is of no use for intuitionism since it can only illuminate the structure of moral language and not its content (Hare 1997, 85-87). This is not a conclusive objection. The linguistic analogy does not require that all of Chomsky's distinctions need to carry over to the moral realm. As I show below, a case can be made that both form and content are part of the moral grammar.

10. As discussed below, the distinction between operative and express principles might be more strongly supported in linguistics than in moral psychology.

11. While it is true that in Trolley cases, we are presented with a choice between two possible actions (saving five vs. killing one), the best interpretation of our intuitive responses to those scenarios according to Mikhail is not that we weigh competing claims against each other, but that we unconsciously analyse the structural features of those situations and then apply (depending on the variation of the Trolley case) e.g. a version of the doctrine of double effect. See Mikhail (2011, chapter 5).

12. This is in line with Ross, who is also interested in what isolated morally relevant features there are, and not in the disagreements that result when different people weigh them differently.

13. Most participants come from the United States or other Western nations. See Mikhail $(2011,331)$.

14. See Mikhail (2011,319-360), especially 339f.; for a critical discussion of this worry, see Enoch $(2013,10)$.

15. For the purpose of keeping the presentation of Mikhail's theory as short as possible, I abstain from describing the relevant cases.

16. The principle helps to explain why variations of trolley cases where a bystander has the chance of saving a man from colliding with a trolley by throwing him off the track and hurting him in the process are commonly judged as permissible.

17. Mikhail $(2011,124)$.

18. In line with the foregoing discussion, Hauser et al. (2007) conclude in a study on whether moral judgments depend on conscious reasoning that while subjects generally failed to provide justifications that could account for the pattern of their judgments (15), a minority of subjects were able to do so.

19. Audi, who sees himself in the tradition of Ross, argues for a list of ten prima facie duties that go beyond Ross's list and also includes items such as the enhancement and preservation of freedom and respectfulness (Audi 2004, 187-196).

20. See the discussion in Ross $(1930,17)$ of why consequentialism fails to explain cases where promises play a role.

21. Even philosophers who are otherwise sympathetic towards Mikhail's research program reject this aspect of his theory. For example, Adam Smith, whom defenders of the moral grammar hypothesis consider a precursor of their view, believed that rules alone are insufficient for arriving at moral judgments. After suggesting an analogy between the rules of grammar and justice in the previously quoted passage, he claims that 'there are no rules by the knowledge of which 
we can infallibly be taught to act upon all occasions with prudence, with just magnanimity, or proper beneficence' (Smith[1759] 2002, 205).

22. For a similar idea, see (McKeever and Ridge 2006, 25-45).

23. Mikhail $(2013,18)$ : '[O]ne can always supplement a theory with one or more 'unless clauses' or auxiliary hypotheses to handle putative counterexamples'.

24. Cases of self-defence provide a good example where a specification might solve the issue with the doctrine of double effect. It does not seem that the fact that I am allowed to kill the attacker if necessary as a means to saving my life is the result of a weighing of the doctrine of double effect against my right to selfdefence. Rather, the fact that I am attacked silences competing considerations that count against my right of self-defence, and this might be incorporated into the formulation of the doctrine.

25. Bernard Williams, on the other hand, is more sceptical about the claim that this position has had many friends in the history of philosophy. See Williams (1995, 184).

26. Further, the existence of duties that pull in different directions provides a plausible explanation of moral regret, a phenomenon that Mikhail's theory cannot easily explain.

27. In his contribution to the discussion about the computational theory of mind, Hubert Dreyfus has argued that parts of our mental operation, especially those having to do with expert knowledge, cannot be captured by an algorithmic procedure. See Dreyfus (1972).

\section{ORCID}

Philipp Schwind (D) http://orcid.org/0000-0003-3577-0614

\section{References}

Aquinas, Thomas. 2012. Summa Theologiae, Vol. 17. The Aquinas Institute.

Audi, Robert. 2004. The Good in the Right: A Theory of Intuition and Intrinsic Value. Princeton, NJ: Princeton University Press.

Audi, Robert. 2013. Moral Perception. Soochow University Lectures in Philosophy. Princeton, NJ: Princeton University Press.

Chomsky, Noam. 1965. Aspects of the Theory of Syntax. Cambridge: MIT Press.

Cuneo, Terence, and Russ Shafer-Landau. 2014. "The Moral Fixed Points: New Directions for Moral Nonnaturalism." Philosophical Studies 171 (3): 399-443.

Dreyfus, Hubert L. 1972. What Computers Can't Do. New York: Harper and Row.

Dwyer, Susan. 2007. "How Good is the Linguistic Analogy?" Vol. 2 of The Innate Mind: Culture and Cognition, 145-167. Oxford: Oxford University Press.

Enoch, David. 2013. “On Analogies, Disanalogies, and Moral Philosophy: A Comment on John Mikhail's Elements of Moral Cognition." Jerusalem Review of Legal Studies 8: 1-25.

Foot, Philippa. 1967. "The Problem of Abortion and the Doctrine of Double Effect." Oxford Review 5: 5-15.

Hare, Richard. 1997. Sorting Out Ethics. Oxford: Oxford University Press.

Harman, Gilbert, and Erica Roedder. n.d. "Moral Grammar." unpublished.

Hauser, Chandra Sekhar, L. Young, and F. Cushman. 2008. "Reviving Rawls's Linguistic Analogy: Operative Principles and the Causal Structure of Moral Actions." Vol. 2 of Moral Psychology: The Cognitive Science of Morality: Intuition and Diversity, 107-144. Cambridge, MA: MIT Press. 
Hauser, Marc D. 2006. Moral MINDS: How Nature Designed our Universal Sense of Right and Wrong. New York: Harper Collins.

Hauser, Marc D., Fiery Cushman, R. Liane Young, Kang-Xing Ji, and John Mikhail. 2007. "A Dissociation Between Moral Judgments and Justifications." Mind \& Language 22 (1): 1-21.

McKeever, Sean, and Michael Ridge. 2006. Principled Ethics: Generalism As a Regulative Ideal. Oxford: Oxford University Press.

Mikhail, John. 2011. Elements of Moral Cognition: Rawls' Linguistic Analogy and the Cognitive Science of Moral and Legal Judgment. Cambridge: Cambridge University Press.

Mikhail, John. 2013. "New Perspectives on Moral Cognition: Reply to Zimmerman, Enoch, and Chemla, Egre, and Schlenker." Jerusalem Review of Legal Studies 8 (1): 66-114.

Railton, Peter. 1986. “Moral Realism." The Philosophical Review 95 (2): 163-207.

Rawls, John. 1971. A Theory of Justice. Cambridge: Belknap Press.

Ross, William David. 1939. Foundations of Ethics. Oxford: Oxford University Press.

Ross, William David. 1930. The Right and the Good. Oxford: Oxford University Press.

Ross, William David. 1977. Aristotle. 6th ed. New York: Routledge.

Sinnott-Armstrong, Walter. 2006. Moral Skepticisms. Oxford: Oxford University Press.

Smith, Adam. (1759) 2002. The Theory of Moral Sentiments. Cambridge: Cambridge University Press.

Sripada, Chandra Sekhar. 2008. "Nativism and Moral Psychology: Three Models of the Innate Structure That Shapes the Contents of Moral Norms." Vol. 1 of Moral Psychology: The Evolution of Morality: Adaptations and Innateness, edited by Walter SinnottArmstrong, 319-344. Cambridge: MIT Press.

Stratton-Lake, Philip. 2014. "Intuitionism in Ethics." The Stanford Encyclopedia of Philosophy (Winter 2016 Edition), edited by Edward N. Zalta. https://plato.stanford.edu/archives/ win2016/entries/intuitionism-ethics/.

Williams, Bernard. 1995. "What does Intuitionism Imply?" in Making Sense of Humanity, 182-191. Cambridge: Cambridge University Press.

Zimmerman, Aaron. 2013. "Mikhail's Naturalized Moral Rationalism." Jerusalem Review of Legal Studies 8: 44-65. 